\title{
Real Impact from the Basel 2 and Basel 2,5 for the Single Bank and How Possible to Reduce the Misunderstanding in Recommendations
}

\section{Talex Maxim*}

Ha Roe 96, Ramat Gan, Israel, 52001, Kfar Yona, Israel

\begin{abstract}
In my report I was motivated to find out the real impact for the Banks from the Operational risk regulatory framework and from the recommendations of the Basel committee in the studying of operational risk impact. This is not a criticism of the practical implementation in work but an invitation to hold the eyes open on the real situation. In this article the theory and practical work description with risk indicators, risk scenario planning, and ways of external data extrapolation. In conclusion there are several questions of the Operational risk and the main issues in the interpretation of external rules and regulations internally.
\end{abstract}

\section{Introduction}

Since the financial crisis of the middle 2007 began the risk measurement policy in the Banks shows the weak points and different miscalculations on line with miss approach for the risk wages accounted for the Capital adjustments. In review of Basel 2 towards new adopted changes in the regulation of Basel 2,5 a lot of discussion appeared in the better approach and recommendations for the market risks capturing and the internal based models implementations for better understanding the external risks influenced from the market. What are missing from my point of view is a straight forward recommendations and descriptions of the Operational risk. In my research in Operational Risk Management Team in Head Office of UniCredit Credit Management Bank S.p.A. (UCCMB) in Verona I was targeting the operation risk studying and looking for the way of improve the risk capturing in the operations.

The outcome from this work I hope will drive up the discussion in the area of Operations and help to improve the existent technique.

\section{Background Information of the Object Studded}

Since 1900 UCCMB is a part of UniCredit Group with Head office in Verona, Italy. It operates with bad debts to minimize the recovery cost. The process is in creation of efficient recovery management taking into consideration all circumstances, conditions and parameters of every single loan provided. In this unity the Operation risk capturing and counting place the main role in understanding the possible losses.

The Clients base of the UCCMB widely diversified: these are the Banks of UniCredit Group; other external Banks and Investment companies. In order to provide a better service UCCMB involves external specialists of differ competent: legal, economic, financial and tax competences and mostly they work in the field of better representative of their Clients in open court settlements and out of court negotiations. The main elements of the business activities are credit purchasing management; credit portfolio evaluation; securitization; independent consulting for companies. Acquisition and selling of real estate assistance with UCCMB assistance goes through connected company TRIVIMM S.p.A.

Understanding of the possible operation risks arising through the operations with the bad debts is crucial for Companies, like observed one. The internal Operational risk Management Team (Team) in UCCMB served for this purpose with main areas of responsibility: reducing, capturing and prediction of possible losses in the process

${ }^{1}$ Bank of Italy [1] of managing the practices with bad debts. The information about the quantity of possible losses extrapolates from the main sources: external losses database, risks indicators, scenario analysis, past internal loss database.

During my 3 month internship I had a target to understand the real impact on business from the Operational side and the ways to measure it. I was wondering - how much the Company can benefit from finding establishing of the appropriate risk measurements and how Company shareholders can be hurt through information undisclosed. Operation risk management framework in UCCMB builds accordingly recommendation of the Italian central Bank and Basel Committee. It handle such processes as: receiving the internal information and interpretation of it in Key risk indicators reports on monthly base, verification of this report with internal risk data base ARGO; verification of internal losses in ARGO system, Scenario Analysis creation and computation the results in ARGO. My role was in careful studying of all processes and activities in work.

\section{Recommendations for the Entity based on Bank of Italy $[1]^{1}$ (theoretical base)}

Basel committee [2] introduced the definition of operation risk in their set of recommendations following up after the crisis 2008. The main difference of the operation risks from others (credit, market) is in relations to the profit of the Company. Operation risk do not considered in profit generation unlike credit and market risks which included in investors' expectations. Meantime the losses, generated through operational risk impact could seriously affect the financial results. In general the comprehensive and fair risk measurement is a target number one for the Basel committee and supervisory bodies. And this work is in ongoing process of improvements and corrections for the better predictions.

*Corresponding author: Talex Maxim, Ha Roe 96, Ramat Gan, Israel, 52001, Kfar Yona, Israel, Tel: +972 58 7754748; E-mail: taimax@yandex.com

Received August 09, 2014; Accepted September 19, 2014; Published September 29, 2014

Citation: Maxim T (2014) Real Impact from the Basel 2 and Basel 2,5 for the Single Bank and How Possible to Reduce the Misunderstanding in Recommendations. Int J Econ Manag Sci 3: 186. doi: 10.4172/2162-6359.1000186

Copyright: (c) 2014 Maxim T. This is an open-access article distributed under the terms of the Creative Commons Attribution License, which permits unrestricted use, distribution, and reproduction in any medium, provided the original author and source are credited. 
Operational risks includes next risk categories:

- frauds (internal and external);

- employee's relations and safety of the workplaces;

- natural damage of actives;

- business and system failure;

This discipline focused on people, systems, processes, natural geographical areas and others factors which are influenced the operational cycle of the Company.

\section{Methods and Models}

There are 3 main methods of Capital adjustments calculation in the operation risk $^{2}$ :

- Basic Approach -based on annual revenue of the financial institution. Among three methods assigned - this is the simplest one and is recommended for the Banks with small share of international activities. In calculation used estimations of average income for the last 3 years. $15 \%$ of value received is the Capital adjustment for the operational risk. This method excludes any year with negative or 0 income performance.

- Standardized Approach - this approach gives the partial degree of flexibility, divided by different activities involved. Range of beta coefficients from $12,5 \%$ up to $18 \%$, applying to each business lines: corporate finance $-18 \%$; trading and sales $-18 \%$; retail banking $-12 \%$; commercial banking - 15\%; payments and settlement - 18\%; agency service $-15 \%$; asset management $-12 \%$; retail brokerage $-12 \%$. Average in 3 years annual gross income in each business line multiplied by beta assigned to each correspondent line. Negative capital charged in any business line may well offset positive capital charges in other business lines. To apply this approach Bank should have: board of directors actively involved in oversight of the operational risk management framework; a conceptual operational risk management system; sufficient recourses in the major business lines as well as audit control in these systems.

- Advanced Measurement Approach - allows the usage of internal empirical risk measurement model for the financial institution. This model is a subject of regulatory approval. Once bank adopt an AMA approach it won't be able to revert this approach to the simpler one without supervisory approval. The minimal requirement for AMA approach usage is similar to the standardized approach. This method includes for data elements: internal and external loss data information; scenario analysis and business environment and internal control factor. Loss distribution is a common approach for all banks in industry: it divides losses into homogenous unit of measurements and for each unit of losses bank constructs two losses distributions -frequency and severity-which provide the whole picture of expected losses in bank. In Advance approach the regulator permits Banks to implement internal models for the calculation of appropriate capital adjustments.

UCCMB, as a part of UniCredit group, works with Standard and Advanced Measurements approaches and supervised by Group Operational Risk (GOR) Department. The operational processes through new technology and other operations activities can generate the losses through next event types, recommended classification from Bank of Italy

${ }^{2}$ http://www.bis.org/publ/bcbsca.htm- Basel II

3JP Morgan - http://www.law360.com/articles/388684/rep-says-jpmorgan-shouldnt-pay-for-bear-stearns-mbs-fraud
- Internal frauds (internal manipulations, employees errors arisen through third party influences, legislations and legal actions which Companies can faced from the internal parties communications (employees relations, employees contracts etc.) and including all internal possible manipulations, errors, sanctions from legal side connected with internal regulations;

- External frauds (frauds from the third party without internal side involvements, third party frauds, robberies, activities against group/ company etc.);

- Securitization and work place safety (includes all processes with employees practice, work place safety, legal employments regulations, half and safety policies regulations etc.);

- Clients, products and business practice (all processes involved the clients actions, climes, risk of losses generated through banking products, losses related to the business activities, etc.;

- Natural damage of actives (this category event includes all natural damage of actives connected with nature, force major and other destructions etc.)

- Processes and errors in system (only technological problems and system errors);

- Execution and process management (losses related with miscalculations, mistakes in contracts with clients and suppliers, back office errors).

Internal regulations of the UniCredit Group adds to the external classification of losses by events types combination of reallocation based on two internal levels within the group classification by products and by geographic areas for better picturing the risks exposure in the regions and in the products of the Group.

Operational risk management Team works with: key risk indicators, scenario analysis; internal loss events and external information for UCCMB separately and after reported the results to the GOR Department of the UniCredit Group. Regulated activities of the Team by main documents of Operational risk framework in UniCredit Group.

Risk indicators serve for on-time signaling of possible losses. It delivers many benefits including risk versus return on-time optimization, achievement of primary business goals through more effective risk management and gives the ideas about possible limitations in processes. Responsible employee in Team monitors historical trend of changes in indicators values and reports this adjustments on a monthly bases. The key risk indicators with at least 12 historical data are recognized in the OpVar calculation and should be flagged in the internal computer system.

\section{Discussion, Weak Points at Work}

In my research I was focused in the estimation of value of the risk for the business with the bad debts and appropriate disclosure of a portfolio which Company obtains. I spent almost a year studying the best practice in risk measurement and risk predictions. I carefully was studying the crisis middle 2007 and particularly JP Morgan frauds case ${ }^{3}$, where was inappropriate and manipulative collateral transformation involved to avoid the manipulative moment in reporting. Moreover I spent a lot of time reviewing a number of publications with examples of the best practice of OpVar calculations with discussions why historical value OpVar is better and more comprehensive than Monte Carlo, 
famous as a black box distribution approach. So I can say that I was quite theoretically prepared to implement all in risk capturing work.

Risk frame work before 2008 paid attention on market risks and credit risks as a major areas of loss generators. Financial institutes improved significantly in risk identifications, measurements and mitigation in these fields in last decade. Meanwhile unpredictably huge losses through uncovered operational activity appeared through crisis in financial market and highlighted that there is much larger losses from frauds and market manipulation which was not included in credit and market risks models. New, slightly more important question for the Basel committee ${ }^{4}$ appeared. Shadow banking system ${ }^{5}$ together with globalization and deregulation in the financial market with sophisticated products delivered a new variable in the risk portfolio of the financial institutions. Underestimated value of the total risk from the management of leading investment banks and world overconfidence in the future delivered one of the biggest disasters in the economic history and showed a role of operation activities in sustainability of the business ${ }^{6}$.

\section{In theory - risk indicators framework includes:}

- Key risk indicators (KRI) - the indicators of loss exposure, showing the value of money in risk. They can appear in any processes with uncertain return (i.e. the amount of money with delay in payments). KRI's are focused on the areas of most significant risk exposure and provides managers with reasonably clear direction of decisions for the losses reduction as well as quick feedback on their effectiveness.

- Basic risk indicators (BRI) - common indicators which provides explanatory information to the KRI, i.e number of customers complaints received, \% in branch performance, number of systemic mistakes, stuff turnover, frequency of trades balance differences appears - anther words - there is the rational thinking that the changes in the range will affect the loss amount.

Only Key risk indicators can participate in VaR calculation. They tell us about value which we can lose today, tomorrow, and day after. Basic indicators are helping to describe the value in terms of where this value occurred, how many practice included, how many days of delay etc.

Key risk indicator should be represented in a monetary value. One of the main reason why is a computer system which used in work, where all data from chosen key risk indicators goes to the VaR estimation. Example of underestimation of OpVar was in case when Key risk indicator consist of numerical parameters instead of monetary value (i.e Value in risk is 5000000 Euro and consist of 25 practice). If will be computed as 25 , computer will realize value of 25 Euro instead of 5000 000; in VaR calculation will be omitted rest of the amount - 4 999975.

Operational risk management Team in UCCMB works only with Key risk indicators, which includes: number of complains, amount of money with delay, number of days without court resolutions etc. The number of indicators presented far over 70 . There was no Basic indicators ever created in the UCCMB, but in the Group in whole the

4"The Basel Committee on Banking Supervision provides a forum for regular cooperation on banking supervisory matters. Its objective is to enhance understanding of key supervisory issues and improve the quality of banking supervision worldwide." - Explanation borrowed from: http://www.bis.org/bcbs/

${ }^{5}$ More about - http://www.investopedia.com/terms/s/shadow-banking-system.asp ${ }^{6}$ Cause of financial crisis (more about) http://www.naic.org/documents/topics white_paper_namic.pdf situation is bit differ: German and Austrian Banks of the Group, where the number of indicators involved is twice less and more comprehensive - Key risk indicators, shows the value in risk or amount of possible losses and - basic indicators serves as comprehensives variables for the better understanding of amount changes. For example: Key risk indicator - amount of money with delay payments over 180 days, Basic indicator - correspondent - number of deals, where delay payments take place in over 180 days.

The different in interpretations of the same theoretical material within the Group identifies the problems in understanding and interpretation of the material not only in separate unit but in the whole organization. It is also questions the work of audit in the Group. From the managerial point of view it is difficult to understand the huge amount of information having different metrics. As for me, I spent one month to get familiar with the indicators in UCCMB. Has management such time for such activities? The situation will be better if within the group will be possible to use the similar metrics, to reduce the number of key indicators, to create basics indicators and made comprehensive working plan where the indicators will be assigned to the events and where will be short description what information this indicator provides and how it is estimated.

One of the main challenges in the Indicators reporting is to make sure that each level of management receives the necessary information for the decision taking. The ways of receiving of the information in risks departments from different part of the business activities should not create additional activity for the main business and not to drag attention through requests of information from the risk management team. Perfect risk management should be invisible and helpful. Now practically monthly risk management team UCCMB collected the information from different departments, after getting the information put it in the programs for transformation and after transferred data goes to the report. Collection of the initial data now is in the responsibility of other departments, which should send this data to the risk management team. It would be better if initial data for risk research risk management team will be capable to collect by themselves. It will reduce the pressure on the other departments and will make the work of the risk department complete.

The control for the other department's work is not the area of responsibility for the Operation risk management Team. The clear and truthful representation of information is a main target. The independent risks teams should not trying to influent on the managers and control them, they are employed to create a process picture for management to understand the risks from the processes which are there at the moment. Operational risks departments are the main business servants and information providers and they should to provide the information and assist to the manager's not otherwise (Table 1).

\section{Scenario Analysis}

Scenario Analysis employed to assist in defines the "unexpected" losses through rare events. It is a way of prediction the largest possible losses for the Company in a worst case scenario once in ten or forty years. It is an approach for the prediction of the future which gives management an opportunity to regulate the business activities, through possibility to construct the mitigation actions like risk transfer (insurance, other transformation to the third party); risk acceptance (provision); risk avoidance (reducing activities, outsourcing, etc). Annually Scenario planning has to be reviewed. If this year scenario gives less expected value than previous one, than management take into consideration in future planning the previous year scenario. Idea 
Citation: Maxim T (2014) Real Impact from the Basel 2 and Basel 2,5 for the Single Bank and How Possible to Reduce the Misunderstanding in Recommendations. Int J Econ Manag Sci 3: 186. doi: 10.4172/2162-6359.1000186

Page 4 of 6

\begin{tabular}{|c|c|c|c|c|}
\hline Area & & Sub Area & Risk type & Risk monitored \\
\hline \multirow{3}{*}{ A } & A & Management extrajudicial practice & CPBP & \multirow{3}{*}{ Operations (Fraud or improper operation) } \\
\hline & B & Management judicial practice & EF & \\
\hline & C & Court resolutions & EDPM & \\
\hline \multirow{2}{*}{ B } & A & Administration accounting & EF & \multirow{2}{*}{ Reputation (Administrative sanctions) } \\
\hline & C & Complains & EF & \\
\hline $\mathrm{C}$ & A & Sensetive correspondence & CPBP & Operations (Fraud or improper operation) \\
\hline \multirow{2}{*}{$\mathrm{D}$} & A & Court management of credit & CPBP & \multirow{2}{*}{ Operations(Missing data) } \\
\hline & B & Judicial management of credit & EDPM & \\
\hline$E$ & A & Personal & EPWS & Operations (Frauds) \\
\hline $\mathrm{F}$ & A & IT Errors & BDSF & Operations (capacity) \\
\hline \multirow{2}{*}{ G } & A & Counts of tax evasion in days & EDPM & \multirow{2}{*}{ Operations (others) } \\
\hline & B & Indagini penali & $\mathrm{EF}$ & \\
\hline \multirow{3}{*}{$\mathrm{H}$} & A & Fraud office to approve & EDPM & Operations (late liquidation) \\
\hline & B & Frods others & EDPM & \multirow{2}{*}{ Operations (errors in payments) } \\
\hline & C & Payments with delay & EDPM & \\
\hline I & A & Incasso & BDSF & Operations (late input) \\
\hline \multirow{3}{*}{$\mathrm{J}$} & A & Cases with payments delay in mortgages more than $90 \mathrm{~d}$ & EDPM & \multirow{3}{*}{ Operations(guaranty in the loan support) } \\
\hline & B & Mortgage expired & EDPM & \\
\hline & C & Mortgage with system errors & EDPM & \\
\hline \multirow{2}{*}{$\mathrm{K}$} & A & Cases with missing data in system & BDSF & \multirow{2}{*}{ Operations (Missing data) } \\
\hline & B & Cases without movements accounted by system & EDPM & \\
\hline & & \multirow{10}{*}{${ }^{*}$ Risk type } & DPA & Damage of physical assets \\
\hline & & & EF & External fraud \\
\hline & & & CPBP & Clients, products and business practices \\
\hline & & & IF & Internal fraud \\
\hline & & & \multirow{2}{*}{ EDPM } & Execution, delivery and \\
\hline & & & & process management \\
\hline & & & \multirow{2}{*}{ EPWS } & Employment, practices and \\
\hline & & & & workplace safety \\
\hline & & & \multirow{2}{*}{ BDSF } & Business disruption and \\
\hline & & & & systems failures \\
\hline
\end{tabular}

Table 1: Structure of the risk indicators in Alphabetical order.

here is in choosing the worst of the worst case for better capturing the extreme event.

Scenario Analysis doesn't try to show exact picture of the future, but in present it generates several alternative projections and the outcome what might be generated from the business activities. It based on prospective, future development and independent from the past. Historical data observation is not expected to be valuable here, instead this type of analysis tries to capture the turning points, which may or may not be connected to the past. Only extremely rare past events are relevant here and pat trend is irrelevant for future outcome. It is necessary to use the detail description of the method, used in Scenario observation and the weaknesses of prediction should be discussed. In the Analysis prediction used to observe best, worst and most likely scenario. More than 3 outcomes from one Scenario could make the analysis unclear. The principle of Scenario Analysis is in identification the unexpected outcomes, which can occurred even having a very small probability and it should be included in strategic planning. Scenario Analysis performs a stress testing. Outcome can be formed mathematically of statistically taking in account possible variability within single scenario as well as possible relations between scenarios.

In UCCMB Scenario Analysis predicts value in 1:10 years like best case of the worst and 1:40 years as a worst case. For simplification GOR recommendation for value 1:40 is no greater than approximately 3,5 times value $1: 10$. Scenario analysis which overestimates this value would be rejected by the program. Relevant critique of this method here is that Scenario Analysis is reported without some important parameters of accuracy (standard errors, confidence intervals, metadata, standardization and coding, error in expert opinion, samples in practice accounted, etc.). These make Scenario Analysis a poor second traditional prediction: specific sensitivity is undefined. It can question the relevance of all Scenario Analysis, prepared by Operation team in UCCMB. In the scenario analysis creation I was wondering how truly the picture can be estimated through 10 and moreover 40 year's period. And as a small example of possible irrelevance of the scenario in simple figures of portfolio changes through 2008 to 2011 in UCCMB, where Table 2 shows the sharp growth of own portfolio UCCMB.

As well as Scenario Analysis should be comprehensive and provides a feed back in circumstances which is most likely appears in a future driven by one or another factor. Aim of Scenario Analysis is to evaluate a risks from particular plan or actions according to situation which could be I case of some changes driven by certain unexpected events. Scenario Analysis can answer the particular question "what happened if", but it should not include events with very low probability. In UCCMB one of scenarios suggests that during earthquake all property in one of the regions - Sicily would be totally destroyed. - Without any historical, geographical data it is impossible to build this hypothesis from nowhere, moreover put it all into a risk report having all property covered by insurance. More logical here is to show the evidence of changes in the property pricing all over the country. As an example 
Citation: Maxim T (2014) Real Impact from the Basel 2 and Basel 2,5 for the Single Bank and How Possible to Reduce the Misunderstanding in Recommendations. Int J Econ Manag Sci 3: 186. doi: 10.4172/2162-6359.1000186

Page 5 of 6

\begin{tabular}{|c|c|c|c|c|c|c|c|}
\hline \multicolumn{8}{|c|}{ Original gross book value (mil. $€$ ) } \\
\hline Portfolios & Dec. 31, 2011 & Dec. 31,2010 & Nov. 30, 2009 & Dec. 31, 2008 & 2011 vs 2010 & 2010 vs 2009 & 2009 vs 2008 \\
\hline UniCredit Group & 17,09 & 23,19 & 18,09 & 12,39 & $-26 \%$ & $28 \%$ & $46 \%$ \\
\hline Own portfolio & 10,23 & 0,49 & 0,08 & 0,09 & $2009 \%$ & $506 \%$ & $-9 \%$ \\
\hline Third-party & 14,38 & 14,83 & 14,83 & 14,97 & $-3 \%$ & $0 \%$ & $-1 \%$ \\
\hline Total & 41,70 & 38,50 & 33,00 & 27,45 & $8 \%$ & $17 \%$ & $20 \%$ \\
\hline
\end{tabular}

*Source: Data between 2010, 2009 and 2008 can't be accurately measured due to undisclosed $4^{\text {th }}$ quarter of 2009.

Table 2: Assets under Management.

I reviewed two papers: Real Assets and Capital Structure" by Murillo Campello and Erasmo Giambona, "Long-Run Productivity Risk and a New Hope for Production-Based Asset Pricing?" by Mariano Massimiliano Croce. And based on that I would like to suggest the future development of the topics of the risk in Capital Structure and adjust several elements, like: volatility of tangible assets and leverage into estimation. Estimation of the index in structure of tangible assets in the business cycle of the firm will improve return on equity and drive the company in more sustainable position in the market. Monitoring volatility impact on the Companies balance results will connect the elements in research (variability in the level of leverage and in fix assets and variability in P/E ratio) and help to understand the interconnections of the elements involved.

In the paper "Real Assets and Capital Structure" by Murillo Campello and Erasmo Giambona ${ }^{7}$ investigates the fixed asset by studying their structure and analyzing the influence of different type of assets on the leverage of the Company. The paper discusses the direct influence of the underlying assets (buildings, lands, equipments etc.) on the borrowing facilities of the Company and dependency of the value of these assets from the current market. More precise the paper discusses the possible outcome from the increase of supply of real estate in the market and how it can affect the Company borrowings facilities. ${ }^{8}$ Based on the decomposition of PP\&E structure test, the paper reports new findings in the relation between assets tangibility and leverage based on the ability to redeploy the assets of the Company. At the basis the paper replicates standard capital structure test using ratio PP\&E to total assets and Company leverage then the observation of the economic effects on the separate assets (land, buildings, etc.) like a part of tangible assets - new in the literature and comes from the different categories of assets involved in the Company structure. Studies involves estimation of liquidity which these assets might generate under the second market condition in certain period of time under certain conditions in the economy owns by Company. ${ }^{9}$ Further development of this studying produce the frame identification of the firms which are most luckily will face credit frictions (small vs. large size firm). Paper provides a systematic evidence of how the credit supply effects leverage across Companies, times and industries and through redeploy ability of the

${ }^{7}$ Journal of Financial and Quantitative Analysis Vol. 48, No. 5, Oct. 2013, pp. 13331370

Copyright 2013, Michael G. Foster School of Business, University of Washington, Seattle, WA 98195 doi:10.1017/S0022109013000525

${ }^{8}$ Defense Base Closure and Realignment Act of 1990

${ }^{9}$ The Defense Base Closure and Realignment Act of 1990 (DBCRA)

${ }^{10} \mathrm{Cite}$ this article as: Mariano Massimiliano Croce, Long-Run Productivity Risk, Journal of Monetary Economics, http://dx.doi.org/10.1016/j.jmoneco.2014.04.001

${ }^{11}$ Fama (1981, 1990), Cochrane (1996), and Balvers and Huang(2007), among others [4], have already documented the existence of a relevant link between the movement in asset prices and real economic activity at business cycle frequency

${ }^{12}$ Boldrin et al. (2001); Bansal and Yaron (2004)

${ }^{13}$ These preferences disentangle the intertemporal elasticity of substitution (IES) from the relative risk aversion coefficient (RRA) and are sensitive to the intertemporal distribution of risk. tangible assets affects capital structure.

More about that you can see also in:- limitation and incompetence of reductions in the firm's assets towards external finance; distress of tangible assets - redeployments and high debts capacity; higher debt capacity potential in the assets which are non-firm-specific; Gavazza - redeployability of the asses and secondary market; Schlingemann, Stulz, and Walkling, Campello - proxies for the volume of transactions of second-hand machinery and equipment in the industries; MacKay and Phillips and Garmaise - on industrial workforce, which affects capital; Bernanke and Gertler - extent to which credit frictions bind and affect firm behavior is often a function of the state of the economy;

Faulkender and Petersen - higher leverage of the firms with credit ratings; Lemmon, Roberts, and Zender's - leverage model determines that traditional determination of the leverage becomes irrelevant once time variance take place in and has limited ability in explaining this variations; Benmelech - variation in the width of track gauges of $19^{\text {th }}$ century railroads and asset salability; Ortiz-Molina and Phillips - liquidity of the assets implies cost of capital; Chaney, Sraer, and Thesmar, also Gan - shocks in the market of real estate affects an ability to invest; Lemmon and Roberts - credit supply shock collapse of bond market 1989;

And the second adjustment for scenario could be borrowed from the paper: "Long-Run Productivity Risk. A New Hope for ProductionBased Asset Pricing?" by Mariano Massimiliano Croce ${ }^{10}$. In this paper are a number of curious techniques and suggestions of measurement of equity premium through productivity risk as a major driver of productivity growth and important component in determination of macro quantities and asset pricing through convex capital adjustments and cost reallocation between consumption and investment produced. The Paper involves studying aggregate productivity ${ }^{11}$ and deeper investigates the specific impact of different sources of productivity on the stock price involving the role of volatility in the long time period in production cycle. Paper includes the long-run productivity risk studied by Bansal and Yaron [3] and consists of a two steps: analysis of documents on the existence of the predictability in US productivity growth; and the second one is a proposal of a new production-based general equilibrium (DSGE) model with long-run productivity shocks which will improve asset pricing [4-10]. The Model improves predictability of productivity growth based on investments and delivers a better equity premium calculation without high correlation between return and consumption growth and implies low risk- free rate in data observed. Relevance between volatility and quantities in assets returns allows conclude that as more sensitive friction as less quantities in return. Paper also studied labor and investments impact as different frictions of the capital ${ }^{12}$.

Paper referees the current long -run risk literature and macroeconomic literature including the deviations of assets prices in a short and in a long run perspective [10-18]. Paper study based on: Epstein and Zin and Weil, - consumer preferences ${ }^{13}$; Jermann convex adjustment costs; Zhang, Liu et al., and Li and Zhang- standard 
Citation: Maxim T (2014) Real Impact from the Basel 2 and Basel 2,5 for the Single Bank and How Possible to Reduce the Misunderstanding in Recommendations. Int J Econ Manag Sci 3: 186. doi: 10.4172/2162-6359.1000186

q-theory; Rouwenhorst, Jermann, Lettau and Uhlig, Boldrin et al. [3] and Cochrane [4]- modern DSGE models; Tallarini- marginal impact on quantities.

\section{Conclusion}

In my article I was hoping to raise the further discussion of possible improvements in the instructions and regulatory framework connected to the better understanding of the risks from the operations and from the business activities, which are from my point of view still need to get some improvements and clarifications. In the future the subject needs to be improved and it is necessary to estimate the proportional elements in the tangible assets and the optimal leverage for the Company and investigate the effect of these elements on the equity premium. I am expected that lower leverage will affected the decrease in equity premium value and decrease in average cost of capital for Company and vise versa. Maintaining the higher leverage can force Company to lose a control on business and from investor point of view make shares of the Company less attractive because of lower equity premium. The verification of hypothesis is important for understanding the role of underlying assets of the firm in the profitability and contribution to the equity premium. The results expected to be different from industry to industry due to the different assets structure. But in general it will identify the optimal assets combination for liquidity maintenance and equity premium improvement.

Under over-reacting/under-reacting operation risk management in organization with continuous risk investments incremental return will be actually negative. Through bad planning overreaction consumes a lot of hours and adds additional activities for other departments: it's generates additional losses and the case where the institutions have zero or very little effort in controlling such risks is actually better off ${ }^{14}$.

\section{References}

1. Bank of Italy, Open publications.

2. Basel Committee on Banking Supervision ,BCBS.

3. Catarineu-Rabell E, Jackson T (2005), Procyclicality and thte new Base accord-banks' choice of loan rating system, Economic Theory 26: 537-557.

4. Fama (1981, 1990) Cochrane (1996), Balvers and Huang (2007), among

${ }^{14}$ Internal documents of UniCredit Group and UCCMB were excluded from the list others, have already documented the existence of a relevant link between the movement in asset prices and real economic activity at business cycle frequency.

5. Bank of England (2009) "Financial Stability Report," Issue No. 26, December 2009.

6. Brunnermeier, Markus, Andrew Crockett, Charles Goodhart, Avinash Persaud and HyunS ong Shin (2009) The Fundamental Principles of Financial Regulation 11th Geneva Report on the World Economy.

7. Buehler, Samandari, Mazingo (2010) Capital ratios and financial distress: Lessons from the crisis, Working Paper, McKinsey \& Company.

8. Committee of European Banking Supervisors, CEBS, (2008) Proposal for a common EU definition of Tier 1 hybrids, April 2008.

9. Committee of European Banking Supervisors, CEBS, (2009), Position paper on a countercyclical capital buffer, 17 July 2009.

10. Commodity Futures Trading Commission, CFTC letter May 13, 2008

11. Corcostegui CL, Gonzalez-Mosquera, Marcelo A, Trucharte C (2003) Analysis of procyclical effects on capital requirements derived from a rating system presented at the workshop "Banking and Financial Stability: A Workshop on Applied Banking Research", Rome, Italy.

12. Estrella A, Park S, Peristiani S (2000) Capital Ratios as Predictors of Bank Failure, FRBNY Economic Policy Review, July 2000.

13. Peter Miu, Bogie Ozdemir, Giesinger Michael (2010) BMO Financial Group, Can Basel III work? - Examining the new Capital Stability Rules by the Basel Committee a Theoretical and Empirical Study of Capital Buffers.

14. Goodhart CAE, Persaud AD (2008) How to Avoid the Next Crash, Financial Times, January 30 .

15. Gordy M, Howells B (2006) Procylicality in Basel II: Can We Treat the Disease Without Killing the Patient?, Journal of Financial Intermediation, 15: 395-417.

16. Jensen, Michael C, William H, Meckling (1976) Theory of the Firm: Managerial Behavior, Agency Costs and Ownership Structure, Journal of Financial Economics, 3: 305-360.

17. Jokipii T, Milne A, (2008) The cyclical behavior of European bank capita buffers, Journal of Banking and Finance, 32: 1440-1451.

18. Kashyap A, Stein J (2004) Cyclical implications of the Basel II capital standards, Economic Perspectives :18-31. 